\title{
A Esfera Pública de Habermas e o Mercado da Comunicação: justificativas para a Regulação dos Meios
}

\section{Habermas' Public Sphere and the Communication Market: Reasons for Regulation of the Media}

1 Raphael de Andrade Naves navesdireito@gmail.com

1 Centro Universitário Salesiano de São Paulo, UNISAL.

\section{RESUMO}

Tema relevante nos dias atuais, o fluxo comunicativo relacionado ao debate público recebe especial atenção neste trabalho, o qual se debruça sobre as falhas existentes no mercado de comunicação social que justificariam uma intervenção estatal, de modo a promover a regulação da mídia. Para tanto, parte-se dos escritos de Jürgen Habermas, de seu conceito de esfera pública, analisando-se o papel da mídia nesse contexto. Adiante, reflete-se sobre a vinculação da atividade comunicativa dos periodistas e das empresas em si aos preceitos éticos e morais abarcados por nossa sociedade, com especial enfoque na liberdade, que é inerente à profissão jornalística.

\section{PALAVRAS-CHAVE}

Esfera pública; ética; moral; comunicação; mercado; regulação da mídia.

\section{ABSTRACT}

A relevant theme nowadays, the communicative stream related to public debate receives special attention in this paper, which looks at the gaps of the media market, which would justify government intervention in order to promote media regulation. For this purpose, we start from the writings of Jürgen Habermas in his concept of public sphere, analyzing the role of media in that context. Then we reflect on the linking of the communicative activity of journalists and companies to ethical and moral precepts embraced by our society, with special focus on freedom, that is inherent to the journalistic profession.

\section{Como você deve citar?}

NAVES, Raphael de Andrade. A Esfera Pública de Habermas e o Mercado da Comunicação: justificativas para a Regulação dos Meios. Cadernos UniFOA, Volta Redonda, n. 29, p. 49-59, dez. 2015. 


\section{INTRODUÇÃO}

Em uma sociedade democrática, os mais variados discursos - não importando o quão repugnantes ou incômodos possam parecer - devem ser objeto de livre circulação, a fim de que, no seio da esfera pública, a sociedade civil agasalhe os que mais the agradarem, formando os valores dominantes, os quais serão observados pelo Estado, em um segundo momento, quando da elaboração das políticas públicas.

Nesse sentido, o mercado de ideias deve ser o mais livre possível. Contudo, como se observará no decorrer do trabalho, o mercado da comunicação social tende a apresentar as falhas, as quais clamam por uma atuação estatal que venha a regulá-lo, de modo a aperfeiçoar a atuação dos envolvidos.

Assim, o presente trabalho tem como objetivo geral apresentar os principais aspectos relacionados à esfera pública pensada por Jürgen Habermas, frisando o papel a ser desempenhado pela mídia no seio do debate democrático.

Em seguida, como objetivo específico, será analisado de que modo os fundamentos éticos e morais se relacionam com a atividade comunicativa desempenhada pelos jornalistas e o seu dever - e não o direito - de serem livres.

Ainda como objetivo específico do trabalho, refletir-se-á sobre as falhas existentes no mercado da comunicação social, o que justificaria sua regulação.

\section{MÉTODOS E TÉCNICAS}

O presente trabalho tem, como referencial teórico, os escritos de Jürgen Habermas. Assim, partindo da revisão bibliográfica de sua teoria democrática, passa-se ao estudo da esfera pública, analisando-se o papel da mídia no fluxo comunicativo, com especial atenção às influências fortemente exercidas no debate público.

Prosseguindo-se com a pesquisa documental, debate-se, sob o prisma ético-moral, se a liberdade seria direito ou dever do jornalista, o que culmina com a análise da literatura existente sobre a regulação do mercado da informação, no qual os meios de comunicação exercem o protagonismo.

\section{DESENVOLVIMENTO}

Jürgen Habermas, sociólogo e filósofo alemão, destinou muitos de seus estudos à formulação de uma teoria voltada ao desenvolvimento do conceito de democracia deliberativa, o qual introduz a sociedade civil como participante da regulação da vida coletiva.

Para tanto, contrapõe os modelos liberal e republicano, em uma defesa do modelo deliberativo de democracia.

No modelo liberal, o processo democrático promove a intermediação entre a sociedade e o Estado. Por meio da política, agregam-se interesses sociais à atuação coercitiva estatal, que continua a exercer o papel central. Assim, a formação da vontade comum seria determinada pelos entes coletivos, os quais, através do agir estratégico fundado em seus próprios interesses, galgariam posições de poder, acumulando os necessários votos. 
Ao se ter em vista o modelo republicano, tem-se a política exercida por meio do entendimento mútuo, com a atuação reflexiva de atores sociais em estado de liberdade e igualdade, o que traria legitimidade ao processo político e colocaria a sociedade como ponto central da política, contrapondo-se ao Estado.

O modelo deliberativo, contudo, se vale de elementos existentes em ambos os padrões, integrando-os em um procedimento de deliberação tido como ideal, desfazendo a noção de contraponto existente entre sociedade e Estado. Assim, a sociedade civil, formadora da opinião pública, convive com os players sociais no interior da esfera pública, através de processos de formação discursiva da opinião e da vontade, estabelecendo um procedimento legítimo de normatização.

Dessa forma, compete aos participantes da esfera pública enfatizar as pressões exercidas pelos problemas vivenciados pela sociedade, não se limitando a percebê-los, devendo identificá-los de modo a serem assumidos e enfrentados no nível parlamentar. Veja-se a assertiva de Habermas:

Para preencher sua função, que consiste em captar e tematizar os problemas da sociedade como um todo, a esfera pública política tem que se formar a partir dos contextos comunicacionais das pessoas virtualmente atingidas. (HABERMAS, 1997, p. 97).

Vale destacar que a sociedade civil não se confunde com a sociedade burguesa, pois o seu núcleo é formado, basicamente, por organizações livres, as quais não possuem natureza estatal e tampouco econômica, restando, tanto à sociedade, quanto à esfera pública burguesa, relegados ao plano histórico.

Para Habermas, um sujeito só faz parte de uma esfera pública como portador de opinião pública, entendida como um juízo que se faz em relação aos demais, representando potencial influência política, o que pode interferir no comportamento eleitoral de seus pares (HABERMAS, 1997). Assim, o surgimento de uma esfera pública significa a percepção de um novo espaço, no qual assuntos de interesse geral seriam não só expostos, como também debatidos, em busca de um consenso.

Como decorrência, quanto mais assuntos forem trazidos para discussão, mais julgamentos acerca da realidade social existirão, aí residindo a esfera de legitimação do poder público.

Dessa forma, a esfera pública política tem, como função primordial, intermediar as relações entre as posições estatais e as necessidades da sociedade, valendo-se, para tanto, da opinião pública. Assim, a sociedade civil pode, com suas opiniões públicas próprias, influenciar o parlamento, de modo a obrigar o sistema político a modificar os rumos do poder estatal (HABERMAS, 1997).

$\mathrm{Na}$ antiga esfera pública burguesa, já mencionada, os espaços públicos físicos eram utilizados para difusão das ideias. Atualmente, já não é possível fixar limites e fronteiras prévios, visto que a esfera pública se mostra como uma estrutura aberta, assim descrita por Habermas:

A esfera pública pode ser descrita como uma rede adequada para a comunicação de conteúdos, tomadas de posição e opiniões; nela os fluxos comunicacionais são filtrados e sintetizados, a ponto de se condensarem em opiniões públicas enfeixadas em temas. (HABERMAS, 1997, p. 92).

Destarte, a esfera pública, por não se tratar de uma organização, não ocupa necessariamente um espaço, cuja ideia se acentua na medida em que os debates podem ocorrer de modo difuso, sem a presença física de seus integrantes, seja através da rede mundial de computadores ou pela mídia, a qual exerce tal mister com protagonismo, o que pode, em dados momentos, tornar-se prejudicial aos interesses coletivos, conforme será visto adiante. 
Habermas também destaca a existência de vários níveis de qualidade da opinião pública emanada da esfera, a depender do grau de racionalidade do debate realizado, ou seja, de seu processo de formação, que é direcionado por especialistas de cada área, com sua expertise, mas dependente dos leigos, também integrantes da esfera pública, na medida em que assentem ou não com determinadas ideias, quando comparadas com suas experiências do cotidiano.

Logo, a esfera pública se presta a identificar e problematizar as temáticas da vida privada, trazendo-as para o debate público, não sendo exatamente o conteúdo que diferencia a esfera privada da pública.

A passagem de um tema da esfera privada para a esfera pública depende da capacidade de cada player articular sua temática, demonstrando sua relevância para o coletivo. No saber de Habermas,

a combinação das associações, dos públicos e dos direitos, na medida em que for sustentada por uma cultura política onde as iniciativas e os movimentos independentes mantêm uma opção política legítima [...] representa um conjunto eficaz [...] em cujos limites é possível reformular o programa de uma democracia radical. (HABERMAS, 1997, p. 104).

Por certo, somente com uma esfera privada livre, na qual os direitos de seus integrantes sejam preservados, é que se verificará a existência plena da esfera pública.

E, como sabido, os agrupamentos da sociedade civil, apesar de sensíveis aos problemas, podem, muitas vezes, carecer de uma maior ressonância de suas ações e pleitos. 0 que se verifica é que as sinalizações que emitem singularmente não possuem a força necessária a influenciar novos processos de aprendizagem no sistema político ou, ainda, traçar novas orientações em processos decisórios (HABERMAS, 1997).

Nesse ponto, entram os meios de comunicação de massa, que têm plenas condições de unir os membros de uma sociedade pensada nacionalmente, em prol de pautas coletivas, representando a esfera pública abstrata, podendo-se falar, até mesmo, em uma esfera global.

Ao serem entregues à sociedade civil, os meios de comunicação de massa tenderiam a ser isentos, não necessitando, em tese, de regulação por parte do poder público, uma vez que ecoariam as vozes dessa própria sociedade.

Contudo, a profissionalização dos meios não basta para estabelecer, per si, uma distinção entre os atores realmente comprometidos com a esfera pública e os que se aproveitam de sua condição e do alcance de sua mensagem.

Como bem observa Habermas, "[...] a crescente complexidade da mídia e o aumento do capital acarretam uma centralização dos meios de comunicação" (HABERMAS, 1997, p. 109), o que afeta sua isenção. $O$ filósofo vai além e indica como identificar se determinado meio está realmente comprometido com a esfera pública.

[...] é necessário observar se eles são sensíveis às ameaças que envolvem os direitos de comunicação, e se estão dispostos a ir além da defesa dos próprios interesses, levantando barreiras contra formas camufladas ou escancaradas de exclusão e de repressão de minorias e de grupos marginalizados". (HABERMAS, 1997, p. 109).

O que se vê nos dias atuais é a crescente perda de isenção dos meios de comunicação de massa, os quais, em sua maioria, não mais representam a sociedade civil, já que dela se desconectaram, privilegiando seus próprios interesses, pautando o debate público do modo oportunista, priorizando a divulgação da informação que mais lhes convêm, desprezando a temática elaborada pelos movimentos sociais. 
Os conglomerados midiáticos passaram a atuar como agentes econômicos, guiados estritamente pelo capital, lutando por obtê-lo a qualquer custo, ainda que o preço a pagar seja menosprezar o papel da esfera pública, fazendo com que o fluxo comunicativo, que deveria partir da periferia para o centro (da sociedade civil para o Estado), faça o caminho inverso (HABERMAS, 1997), servindo a mídia como censora ad hoc e porta-voz dos grupos que ocupam a pirâmide poder econômico e político.

Alguns países latino-americanos, seguindo movimentos ocorridos na Europa e na América do Norte, lançaram mão de uma regulação jurídica dos meios de comunicação, com vistas a diminuir a ação econômica exercida sobre os mesmos, de modo a restabelecer sua neutralidade, em uma tentativa de colocá-los novamente a serviço da esfera pública.

Habermas ainda coloca outro ponto em debate:

O código profissional dos jornalistas e a autocompreensão ética da corporação, de um lado, bem como a organização de uma imprensa livre, de outro lado, [...] expressam uma ideia reguladora bastante simples, que [...] os meios de massa devem situar-se como mandatários de um público esclarecido, capaz de aprender e de criticar, devem preservar sua independência frente a atores políticos e sociais, imitando nisso a justiça. [...] Por este caminho se neutraliza o poder da mídia e se impede que o poder administrativo ou social seja transformado influência em político-publicitária. (HABERMAS, 1997, p. 112).

Sintetiza-se, dessa forma, um ponto pouco explorado no debate nacional acerca da regulação dos meios, já que não basta que se promova a mera regulação das corporações midiáticas - ponto polêmico, comumente debatido e ferozmente combatido pelas empresas do setor -, olvidando-se do dever ético-profissional inerente a cada jornalista.

Por certo, o debate acerca das questões éticas e morais relacionadas ao universo comunicativo exige que se promova uma reflexão sobre a evolução dos meios de comunicação, a dimensão por eles adquirida e ocupada no seio da sociedade e o modo como influenciam as relações sociais.

Não se pode esquecer, ademais, da fluidez com a qual se vivenciam mudanças de conceitos estruturais no âmbito da sociedade civil, privilegiando-se a pluralidade e o necessário respeito aos diferentes.

Da doutrina lusa capitaneada pelo professor João Pissara Esteves, retiramos a observação de que os paradigmas éticos e morais relacionados à atividade comunicativa devem levar em conta "[...] o universo mais amplo da comunicação - aquilo que envolve e funda os próprios media, sempre, numa perspectiva da comunicação pública como teia complexa [...]". (ESTEVES, 2003, p. 146).

Assim, apesar de os meios de comunicação estarem atualmente constituídos como verdadeiras sociedades empresárias, voltadas à expansão de seus negócios e com os dois pés fincados no capitalismo, é certo que, quando exercem suas atividades de modo a privilegiar os fundamentos éticos e morais relacionados ao jornalismo, promovem a ampliação do espaço público - vale dizer, da esfera pública de Habermas -, haja vista que, em tese, difundem os valores morais da sociedade.

Dessa maneira, fomenta-se o debate de ideias e perspectivas, o que contribui para a criação de espaços argumentativos de grande amplitude, valendo-se, muitas vezes, do ambiente digital, no qual os cidadãos são mobilizados de modo quase instantâneo a participarem do debate público, algo que não ocorria em um passado bem próximo, quando predominavam os meios impressos e televisivos.

É de grande responsabilidade, portanto, o exercício de tal múnus, pois, ao se escolher uma determinada manchete em um telejornal, chamada de capa em um jornal impresso ou, ainda, uma chamada na tela inicial de um sítio na grande rede, direciona-se os membros da sociedade a discutirem 
os fatos então noticiados, o que, em última ratio, significa dizer que os meios de comunicação detêm a responsabilidade ímpar quanto à elaboração da pauta dos debates públicos.

Daí a necessidade de se ter uma imprensa livre, não submetida às amarras da censura estatal, porém, devidamente regulada, a fim de que atue como instrumento da democracia, privilegiando o agir comunicativo, em detrimento do agir estratégico. No saber do professor Venício Artur de Lima,

a condição básica para a realização dos direitos políticos da cidadania no mundo contemporâneo é a existência de um mercado de mídia policêntrico e democrático, vale dizer, garantia para que cada um possa exercer plenamente seu direito à comunicação. (LIMA, 2011, p. 215).

Tais considerações, contudo, nos levam à seguinte indagação: seriam os meios de comunicação verdadeiros atores sociais sui generis, na medida em que agem estrategicamente, salvaguardando seus interesses e, ao mesmo tempo, se colocando como uma espécie de foro deliberativo, através do qual os cidadãos debatem e negociam suas ideias e pontos de vista, a fim de encontrar um ponto comum para questões coletivas?

E mais, de que forma os meios de comunicação se relacionam com os princípios éticos e morais?

Prosseguindo na investigação, veja-se o teólogo Leonardo Boff, em uma busca por traçar os parâmetros que diferenciam a ética da moral.

A ética é parte da Filosofia. Estatui princípios e valores que orientam pessoas e sociedades. A moral é a parte da
vida concreta. Trata da prática real das pessoas que se expressam por costumes, hábitos e valores culturalmente
estabelecidos. Uma pessoa é moral quando age em conformidade com os costumes e valores consagrados.
Uma pessoa é ética quando se orienta por princípios e conviç̧ões. Uma pessoa pode ser moral, mas não ne-
cessariamente ética. (BOFF, 2009, p. 37).

Importante destacar, ademais, os apontamentos do professor Pablo Jiménez Serrano, que não se esquece da ética jornalística, ao apontar seu papel de destaque na sociedade:

A Ética aplicada aos negócios, à medicina, ao jornalismo etc. possui, igualmente, papel dominante e alcança cada vez mais um lugar importante na vida social, devido à consequente aplicação de princípios éticos gerais (universais) nas diversas profissões. (JIMÉNEZ SERRANO, 2010, p. 17).

Os desafios vivenciados pelo mercado da mídia serão abordados no próximo tópico. Neste, cuidamos tão somente da postura esperada por aqueles que realmente produzem o conteúdo: os jornalistas que atuam diretamente na ponta, selecionando e produzindo as matérias a serem veiculadas.

Tais profissionais se deparam diariamente com a dicotomia existente em sua atividade, pois, ao mesmo tempo em que em são obrigados a seguirem padrões éticos e morais, estão vinculados a sociedades que, aprioristicamente, não os têm como norte, haja vista a já mencionada busca pelo capital.

Mencionados padrões podem ser encontrados no Código de Ética dos Jornalistas Brasileiros, editado pela Federação Nacional dos Jornalistas, em uma tentativa de autorregulação que carece de efetividade, talvez pela inexistência de um conselho a regular a atividade em nível nacional, de modo coercitivo e sob o amparo da lei.

Outro ponto a se questionar diz respeito à desvinculação do código à atualidade, já que sua última atualização se deu em 2007, época em que a inclusão digital ainda não era uma realidade, sem que haja, contudo, qualquer movimentação para alterá-lo ou, ainda, adequá-lo à atual realidade fática da comunicação social. 
Ao jornalista, por certo, cabe analisar os princípios e valores a se prestigiar no caso concreto, o que o colocará na trajetória da ética, a única que poderá lhe render frutos duradouros e dissociados do pensamento capitalista, outorgando-Ihe a necessária independência profissional, assim vista por Eugênio Bucci:

$\mathrm{Na}$ imprensa, a liberdade encontra de fato uma materialização: ela se traduz no grau de independência dos veículos informativos (e de seus operadores) em relação aos interesses organizados, sejam eles econômicos, políticos, religiosos, sindicais, científicos e assim por diante. (BUCCl, 2013, p. 13).

Tal independência resulta não do direito do jornalista de ser livre, mas sim de seu dever de gozar de liberdade no desempenho de suas funções (BUCCl, 2013), o que não quer dizer que se estaria liberando o meio de comunicação da obrigação de zelar pela informação objetiva, enquanto gestor e, até mesmo, proprietário da mensagem produzida pelo periodista (SANKIEVICZ, 2011).

\section{Ademais, possuem os periodistas o dever de informar}

suas linhas e tendências, de não confundir narrações com valorações e de dar espaço àquelas notícias e comentários que apresentam ou significam a contrapartida do asseverado, em um jogo edificante de bilateralidade da audiência. (MARTINEZ, 2008, p. 25).

Antes de adentrar ao próximo tópico, mister se faz citar, mais uma vez, o professor João Pissara Esteves, que aponta o caminho a se seguir - com o qual compartilhamos -, partindo da premissa de que os códigos deontológicos direcionados aos profissionais da mídia não têm a força necessária para que seus princípios sejam seguidos pelos empresários do setor, senão vejamos:

Há uma intenção de projetar os media como esteios da democracia, tendo por base a função informativa e um conjunto de valores nucleares do jornalismo: verdade, objectividade, neutralidade distanciamento, imparcialidade, etc. $\mathrm{O}$ aspecto ilusório, desta deontologia e que acaba por lhe conferir um caráter irredutível de ideologia é a crença (explícita ou pressuposta) de que os profissionais (os jornalistas em primeiro lugar) têm a possibilidade de condicionar de forma decisiva (impor) o funcionamento democrático dos media, só por si e sem qualquer mudança estrutural mais profunda - ao nível dos próprios media ou da sociedade no seu conjunto. (ESTEVES, 2003, p.149).

Ainda que este trabalho não apresente propostas ou soluções para a problemática colocada, buscando tão somente identificá-la e contextualizá-la, passa-se a abordar, no próximo tópico, as faIhas da comunicação social enquanto mercado, as quais, certamente, culminam em prejuízo à esfera pública pensada por Habermas e aos preceitos éticos e morais a serem obrigatoriamente observados pelos periodistas.

\section{RESULTADOS E DISCUSSÃO}

O ponto de partida, neste tópico, passa imperiosamente pela análise do discurso por seu viés econômico. Por certo, os direitos de propriedade sobre determinada informação são mais fluidos e difíceis de serem mensurados do que os relacionados aos demais bens.

Assim, quando falamos da locação de um veículo por determinado tempo ou, ainda, de um alimento adquirido e consumido, pode-se determinar qual sujeito está fazendo o uso do serviço ou do bem.

Contudo, quando falamos de informação, não podemos nos valer da mesma premissa, haja vista que o mesmo conteúdo informativo pode ser acessado, entendido e compartilhado por um número indefinido de sujeitos, por um custo que, muitas vezes, equivale a zero, não havendo acréscimo, em regra, ao custo de produção, quando outras pessoas acessam a mesma informação, depois de produzida. 
Nesse viés, "a informação, [...] assim como o ar, a defesa nacional e a segurança pública, tende a se tornar um bem comum assumindo características de um bem público" (SANKIEVICZ, 2011, p. 59), o qual, na teoria econômica, é conhecido como aquele que é consumido por várias pessoas juntas, em quantidade por vezes, indeterminada.

Tal característica, contudo, nos parece como indutora de uma falha no mercado da comunicação, já que muitas pessoas podem consumir informação sem remunerar seu produtor, ainda que a norma legal tente diminuir tal impacto, através dos direitos autorais e da regulamentação existente sobre marcas e patentes, por exemplo.

Logo, a demanda sentida pela mídia reflete apenas aquela vinculada aos compradores diretos da informação, havendo, por certo, uma nítida diferença entre o seu valor econômico - facilmente mensurado - e o valor social, sobre o qual este trabalho se debruça.

Por certo, esse é o primeiro ponto relevante para que se defenda uma regulação do mercado da comunicação; o segundo fator decorre do primeiro e se relaciona ao fato de que a corporação possui altos custos para produzir a informação.

Assim, é necessária a existência de uma grande audiência, para que tais custos sejam cobertos, o que traz consequências no seio político, já que as minorias tendem a passar despercebidas, em uma nítida situação de sub-representação perante os meios (BAKER apud SANKIEVICZ, 2011).

Alexandre Sankievicz prossegue:

Um sistema de liberdade de expressão basicamente financiado pela iniciativa privada significa que jornais, revistas, estações de rádio e televisão irão alocar o direito de comunicação levando em consideração principalmente a perspectiva de lucro. (SANKIEVICZ, 2011, p. 70).

E, valendo-se dos ensinamentos de Habermas (1997), pode-se dizer que o discurso de caráter político corresponde ao núcleo protetivo da liberdade de expressão, o que, mais uma vez, justifica a necessidade de regulação dos meios, sabidamente pelo fato de que a informação lançada através de um discurso e/ou debate político, ao assumir a feição pública já esposada, impede seu emissor de colher os benefícios relacionados.

Trata-se de claro incentivo à subprodução e subveiculação de debates de cunho político, o que culmina por escamotear com o valor social de tal vertente informativa, essencial ao pleno desenvolvimento da esfera pública habermasiana.

De outro lado, o discurso comercial - muito mais próximo de um bem de consumo do que o discurso político - é superproduzido e superveiculado, na medida em que se preza seu valor econômico, motivo pelo qual também deve ser regulado, com o fito de nivelar a balança comunicativa.

Não se olvide, contudo, como já se havia alertado, que a sociedade civil é a protagonista do processo de tomada de decisões, motivo pelo qual deve ter pleno e livre acesso às informações, sobretudo as relacionadas aos assuntos políticos (MACHADO JUNIOR; NAVES, 2014).

E, mais do que o periodista da ponta, a regulação em questão há de ser direcionada aos meios de comunicação em si, sob pena de perda da sua eficácia (ESTEVES, 2003). 
Em verdade, a regulação da mídia representa um grande dilema principiológico, já que os entes do setor, para sobreviverem como empresas privadas que são, tornam-se dependentes do sistema econômico, privilegiando informações rentáveis, em detrimento do conteúdo político.

Também, valendo-se da doutrina lusitana, não faltam opiniões contrárias à regulação estatal, por entenderem que o próprio mercado teria condições de promovê-la:

O Estado não tem responsabilidade de promover o pluralismo independentemente da vontade efetiva de participação e de expressão dos diferentes grupos sociais, à revelia do seu próprio desejo de abstinência expressiva, mas tem o dever de respeitar a livre circulação de ideias e opiniões. (MACHADO, 2002, p. 872).

Mais do que respeitar a livre circulação de ideias e opiniões, o Estado tem o dever de fomentá-la. Veja-se:

Nesse equilíbrio delicado e complexo, o excesso na intervenção pode descambar para um Estado totalitário e controlador das manifestações discursivas da sociedade civil, ao passo que a omissão do Estado pode representar a exclusão do discurso público de grupos sociais econômica e politicamente desfavorecidos e a manipulação desse mesmo discurso por grupos hegemônicos que controlam os meios de comunicação de massa. (BINENBOJM; PEREIRA NETO, 2005, p. 4).

E, corroborando com tal assertiva, assim já havíamos nos manifestado:

\begin{abstract}
O Estado deve, então, se abster de interferir na esfera individual, vez que a liberdade de expressão representa uma proteção à autonomia discursiva de seus cidadãos; cabe-lhe, ademais, prestigiar tal liberdade fundamental, haja vista que se trata de instrumento a ser utilizado na promoção da diversidade, exigindo uma prestação positiva estatal, de modo a ampliar o espaço a ser conferido aos mais diversos grupos ideológicos, fomentando o debate no seio democrático. (NAVES; VILLAS BOAS, 2015, p. 8-9).
\end{abstract}

A solução, que passaria pelo custeio estatal direto da diferença entre o valor social e o econômico da informação, teria o condão de criar uma vertente da imprensa livre das pressões econômicas, mas imperativamente sujeita às pressões políticas, as quais são tão perniciosas quanto a outra.

O meio termo, talvez, seja encontrado em uma terceira via, com sociedades privadas seguindo seu instinto econômico - com seus excessos capitalistas sendo alvo de regulação - e outras públicas, financiadas ou geridas diretamente pelo Estado - regulando-se a interferência dos governos no discurso -, participando ambas, cada qual com suas características intrínsecas, da esfera pública pensada por Jürgen Habermas.

\title{
5 CONCLUSÃo
}

Nas sociedades contemporâneas, a esfera pública habermasiana não depende de espaços físicos em que ocorram reuniões para debate e discussão dos temas levantados pela sociedade civil. Como visto, tais deliberações são intermediadas pela mídia, seja ela televisiva, radiofônica ou digital, de modo que as sociedades empresárias que exercem tal mister formam, atualmente, o fórum dominante do debate público.

Por tais peculiaridades, justifica-se a preocupação acerca da garantia da diversidade e da pluralidade nos meios de comunicação, inexistindo, contudo, consenso sobre qual seria o melhor método para se garanti-los.

Em verdade, ao mesmo tempo em que se colocam como uma espécie de foro deliberativo, através do qual os cidadãos debatem e negociam suas ideias e pontos de vista, a fim de encontrar um ponto 
comum para questões coletivas, os meios de comunicação agem estrategicamente, salvaguardando seus interesses, por meio da imposição de pautas que lhes convêm.

Restou demonstrado, portanto, que o mercado de ideias encontra-se muito distante de seu potencial democratizante, em virtude, muitas vezes, da ausência de regulação, de modo que os fundamentos éticos e morais relacionados à atividade comunicativa são deixados de lado, privilegiando-se a busca pelo capital.

Logo, a regulação do mercado comunicativo é medida que se impõe, através de prestações positivas estatais, que venham a ampliar o espaço conferido a grupos ideológicos minoritários e ignorado pela mídia, a fim de que seja fomentado o livre debate de ideias.

Portanto, deixa-se para um segundo momento, a realização de uma análise detida nas propostas hoje existentes de regulação, firmando-se posição crítica acerca das mesmas.

\section{REFERÊNCIAS}

BAKER, C. Edwin. Media, markets and democracy. New York: Cambridge University Press, 2002.

BOFF, Leonardo. Ética e moral: a busca de fundamentos. Petrópolis: Vozes, 2009.

BUCCI, Eugênio. Sobre ética e imprensa. São Paulo: Companhia das Letras, 2000.

A imprensa e o dever da liberdade: a independência editorial e suas fronteiras com a indústria do entretenimento, as fontes, os governos, os corporativismos, o poder econômico e as ONGs. São Paulo: Contexto, 2013.

COSTA, Caio Túlio. Ética, jornalismo e nova mídia, uma moral provisória. Rio de Janeiro: Jorge Zahar, 2009.

ESTEVES, João Pissara. Espaço público e democracia. São Leopoldo: Unisinos, 2003.

FISS, Owen M. A ironia da liberdade de expressão: estado, regulação e diversidade na esfera pública. Trad. e Pref. de BINENBOJM, Gustavo; PEREIRA NETO, Caio Mário da Silva. Rio de Janeiro: Renovar, 2005.

HABERMAS, Jürgen. O papel da sociedade civil e da esfera pública política. In: Direito e democracia: entre facticidade e validade. Trad. Flávio Bueno Siebeneichler. Rio de Janeiro: Tempo Brasileiro, 1997.

JIMÉNEZ SERRANO, Pablo. Metodologia do ensino e da pesquisa jurídica. Barueri: Manole, 2003.

Ética e administração pública. Campinas: Alínea, 2010.

KARAM, Maria Lúcia. Liberdade, intimidade, informação e expressão. Rio de Janeiro: Lumen Juris, 2009.

LIMA, Venício A. A censura disfarçada. In: GUIMARÃES, Juarez (orgs.). Liberdade de expressão: as várias faces de um desafio. São Paulo: Paulus, 2013.

Regulação das comunicações: história, poder e direitos. São Paulo: Paulus, 2011. 
MACHADO, Jónatas. Liberdade de expressão: dimensões constitucionais da esfera pública no sistema social. Coimbra: Coimbra Editora, 2002.

MACHADO JUNIOR, Sérgio Luis Pacheco; NAVES, Raphael de Andrade. A regulação da mídia e a sua importância para a concretização de direitos. In: Anais do III Seminário de Extensão do UNISAL - Direitos Humanos, Culturas e Meio Ambiente. Lorena: Unisal, 2014.

MARTINEZ, Ângela Vivanco. A concentração dos meios de comunicação em sociedades democráticas: perigo para a liberdade de expressão ou condição de subsistência. In: THEMOTEO, Reinaldo (org.). A mídia entre regulamentação e concentração. Rio de Janeiro: Fundação Konrad Adenauer, 2008.

NAVES, Raphael de Andrade; VILLAS BÔAS, Regina Vera. A arguição de descumprimento de preceito constitucional 187. In: NASCIMENTO, Grasiela Augusta Ferreira; VILLAS BÔAS, Regina Vera; SILVA, Daisy Rafaela; MARÍN, Raúl Fernando Núñes (orgs.). Direitos humanos e sociedade contemporânea. Lorena: Unisal, 2015.

RAMPAZZO, Lino. Metodologia científica: para alunos dos cursos de graduação e pós-graduação. 7 . ed. São Paulo: Loyola, 2013.

SANKIEVICZ, Alexandre. Liberdade de expressão e pluralismo: perspectivas de regulação. São Paulo: Saraiva, 2011. 